\title{
Continuous detection and characterization of the Sea Breeze in clear sky conditions using Meteosat Second Generation
}

\author{
I. M. Lensky ${ }^{1}$ and U. Dayan ${ }^{2}$ \\ ${ }^{1}$ Department of Geography and Environment, Bar-Ilan University, Ramat-Gan, 52900, Israel \\ ${ }^{2}$ Department of Geography, The Hebrew University of Jerusalem, Jerusalem, 91905, Israel \\ Correspondence to: I. M. Lensky (itamar.lensky@biu.ac.il)
}

Received: 6 October 2011 - Published in Atmos. Chem. Phys. Discuss.: 19 December 2011

Revised: 20 June 2012 - Accepted: 22 June 2012 - Published: 25 July 2012

\begin{abstract}
The sea breeze (SB) is a thermally induced boundary layer phenomenon that occurs at coastal locations throughout the world. Previous satellite remote sensing studies used low-level clouds formed over the sea-breeze convergence zones to identify the SB. In this study continuous thermal infrared data from a geostationary satellite (Meteosat Second Generation) and concurrent field measurements were used to detect and characterize the SB in clear sky conditions during the summer. Surface data (wind speed and direction) from 11 sites over Israel for ten summer days in July 2010 for three different synoptic circulation categories were selected.

In order to assess the impact of the synoptic induced flow on the SB, we looked for the best agreement between surface and satellite SB timing. An independent classification of synoptic categories performed for the ten summer days revealed two distinct patterns of the SB. During weak horizontal pressure gradient (Weak Persian Trough and High to the West), which enables full development of the SB, the timing of the SB from satellite and field measurements were well correlated $\left(R^{2}=0.75\right)$, as compared to unfavorable atmospheric conditions (Deep Persian Trough) yielding lower value $\left(R^{2}=0.5\right)$. The $\mathrm{SB}$ was identified by surface measurements in an earlier time of the day, with respect to the satellite column integrated measurements.

Visualizing timing of the SB retrieved from satellite data enabled distinction of SB behavior under different synoptic categories. Over desert regions the strong thermal contrast enables detection of the SB even under suppressing synoptic conditions (Deep Persian Trough).

This method enables detection and timing of the SB over desert regions where clouds and field measurements are scarce, and is applicable worldwide.
\end{abstract}

\section{Introduction}

The sea breeze (SB) is a boundary layer phenomenon that occurs at coastal locations throughout the world and probably the most analyzed mesoscale circulation system. It is caused as a response to thermal forcing generated by the daytime differential surface heating between land and sea. This heating creates a corresponding horizontal pressure gradient that enables cool marine air to propagate inland. The SB is also influenced by the strength and direction of the synopticscale wind patterns. Over sub-tropical regions such as the East Mediterranean (EM), it is a phenomenon of the summer season when the land-sea temperature difference is the largest and weaker large-scale winds prevail.

Ample studies of this phenomenon have been devoted to analytic aspects (e.g. Young and Zhang, 1999; Qian et al., 2009; Dalu et al., 2003), observational aspects (e.g. Drobinski et al., 2006; Federico et al., 2010; Azorin-Molina et al., 2011) and to numerical modeling (e.g. Chen et al., 2011; Crosman and Horel, 2010; Grønås and Sandvik, 1998; Papanastasiou et al., 2010a; Rao et al., 2011; Soler et al., 2011).

The impact of this thermally induced circulation is of many facets. It plays an important role on human comfort by suppressing daytime thermal stress associated with heat wave events (Papanastasiou et al., 2010b), on migrating soaring birds which exploit the updraft associated with the sea breeze converging lines (Alpert et al., 2000), and on cross shore transport of marine nutrients across the continental shelf (Hendrickson and MacMahan, 2009). Pollution levels mainly over coastal cities (Mangia et al., 2010; Papanastasiou and Melas, 2009) are also often associated with the land and sea breeze (LSB) air mass horizontal recirculation. This process refers to the rotation of the wind direction due to the diurnal cycle of the LSB causing a polluted air mass to return 
to its source region the next day contributing to an increase of pollution levels (Levy et al., 2008).

Significant progress in remote sensing of essential atmospheric parameters and their derived phenomena was made during the last two decades. This improved much our understanding of fundamental processes within the atmospheric boundary layer such as LSB. Azorin-Molina et al. (2009) used daytime polar-orbiting environmental satellites (POES) to obtain spatial distribution of convective areas associated with the sea breeze over the Iberian Mediterranean zone. They identified the location of preferential sea-breeze convergence zones in relation to the shape of coastline and orographic effects. Additionally, they used mean boundary layer wind speed and direction to provide statistics about the effect of prevailing large-scale flows on sea-breeze convection.

Damato et al. (2003) also used daytime POES to estimate the occurrence of sea breeze fronts (SBF) in Western Europe and their inland penetration. They concluded that their method and its results showed two main limitations:

i Days with clear sky were excluded even though a surface land-sea thermal gradient and weak prevailing wind could allow sea-breeze development and inland penetration.

ii The satellite data were collected at non-homogeneous hours in early afternoon. Therefore, the analysis did not take into account the maximum inland penetration of the SB.

Planchon et al. (2006) overcame the second limitation by using geostationary satellite data (GOES-8) to locate the maximal penetration of the SB adopting a similar methodology, i.e. identifying low-level clouds.

Here we will demonstrate a new objective method to detect the timing of the SB using continuous sequences of data from geostationary satellite that does not rely on the presence of clouds, but rather on thermal infrared radiation emitted from the surface in clear sky conditions. This approach fills the gap of both abovementioned limitations.

In this study, wind speed and direction from surface meteorological data over Israel are used concurrently with the satellite data. Since synoptic conditions affect the SB circulation and its spatiotemporal behavior, the three typical sealevel pressure (SLP) synoptic categories in the summer over the EM were analyzed. These are the weak and deep modes of the Persian trough (WPT and DPT respectively) and High to the West (HW). The Persian trough is an extension of a low-pressure system over the Persian Gulf reaching the EM region. The HW synoptic configuration extends from the Azorean High. All three types advect cool and moist marine air at shallow atmospheric layers from the Mediterranean Sea onshore. Synoptic conditions favorable for mesoscale thermally induced SBs are characterized by weak large scale forcing (Klaić et al., 2009; Planchon et al., 2006) allowing for mesoscale phenomenon to come into effect. Levy et al. (2008) based on a quantitative measure of wind recirculation found a high frequency of mesoscale dominant flows as being attributed to weak synoptic scale forcing, namely, the WPT and HW flow patterns.

Numerous analytical and model derived studies on the SB behavior over Israel have been published. In one of the earliest studies, Neumann and Mahrer (1971) improved Estoque's model based on some modifications made so as to circumvent the violation of mass concentration. Alpert et al. (1982) developed a model to simulate the sudden incursion of the cool Mediterranean SBF to the EM in the summer months, however, they pointed at inaccuracies in the model's prediction of the time of onset of the strong winds characterizing the SBF penetration.

The following section will demonstrate a method to detect the SB in a single location using concurrent time series of surface meteorological data and geostationary satellite data from one pixel. In section three, results from the remote sensing analysis will be presented, along discussion on the influence of different synoptic categories on the SB spatiotemporal characteristics. A summary section will close this paper.

\section{Data and methods}

Surface and $500 \mathrm{hPa}$ reanalysis data, and radiosonde data are used for the synoptic classification, which is described in the next section. Wind speed and direction from surface meteorological data are used for local in-situ detection of the SB, while satellite data for a broad coverage of the SB timing and onshore penetration. The detection of the timing of the SB from satellite data is based on the thermal contrast between cool marine-air and underlying warm terrain and is performed independently from surface data (see animation of the SB from the MSG satellite used here in the Supplement). In order to assess the impact of the synoptic induced flow on the SB, we looked for the best agreement between surface and satellite SB timing. An independent classification of synoptic categories performed for the ten summer days revealed two distinct patterns of the SB, which will be presented and discussed in Sect. 3.

\subsection{Meteorological data}

Surface meteorological data of fine temporal resolution over Israel were made available in recent years. Figure 1 shows the location of the meteorological stations that were used here. In order to select adequately days representing the three synoptic categories, we analyzed summer days from July 2010. For the selection, three quantitative criteria were applied: the depth of the horizontal pressure gradient of the synoptic system, the depth of the atmospheric boundary layer and the ventilation coefficient (VC). VC is the mixed layer depth multiplied by the mean wind speed in the mixed layer, a common parameter to assess the dispersion conditions of 


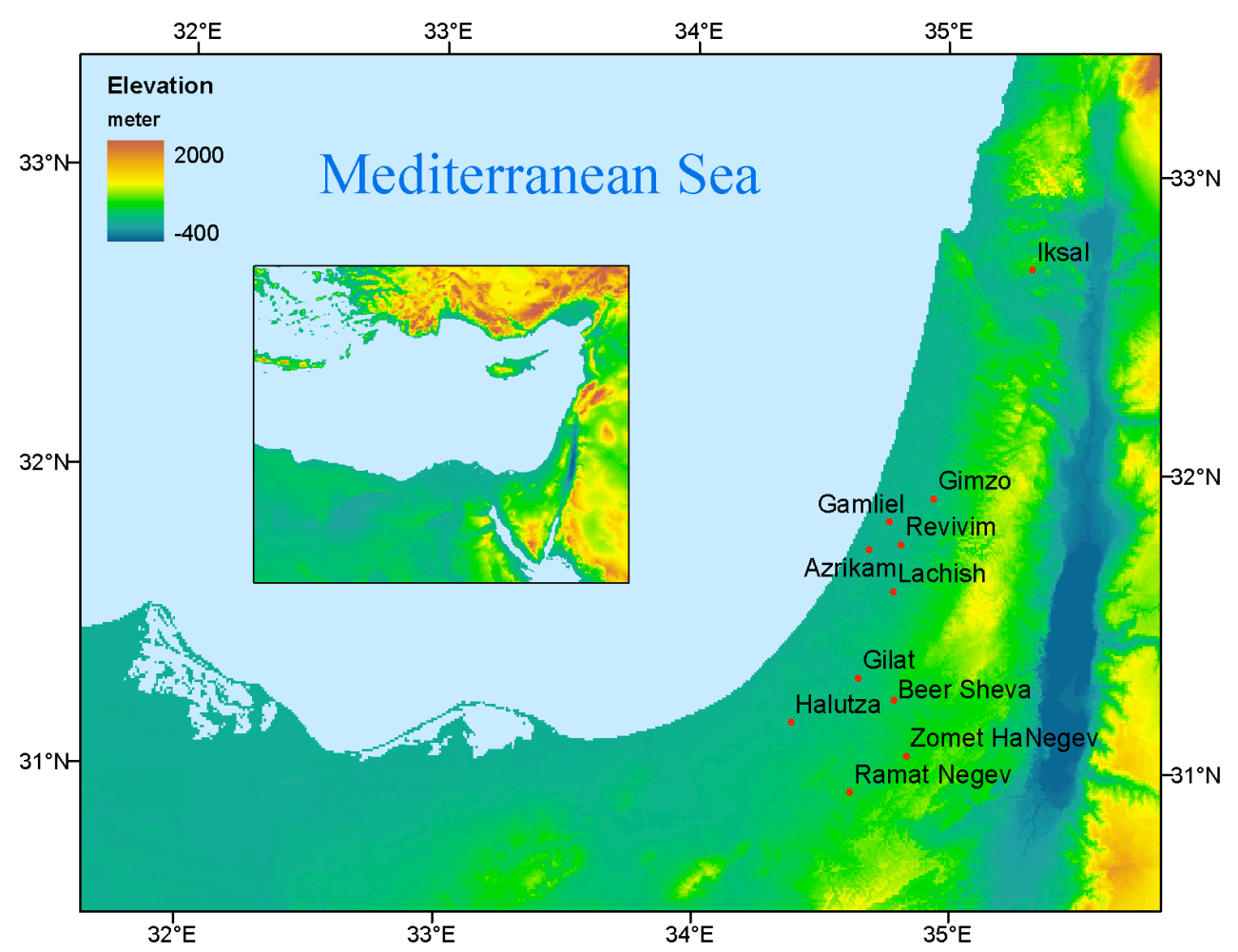

Fig. 1. Location of the meteorological ground stations and the local topography.

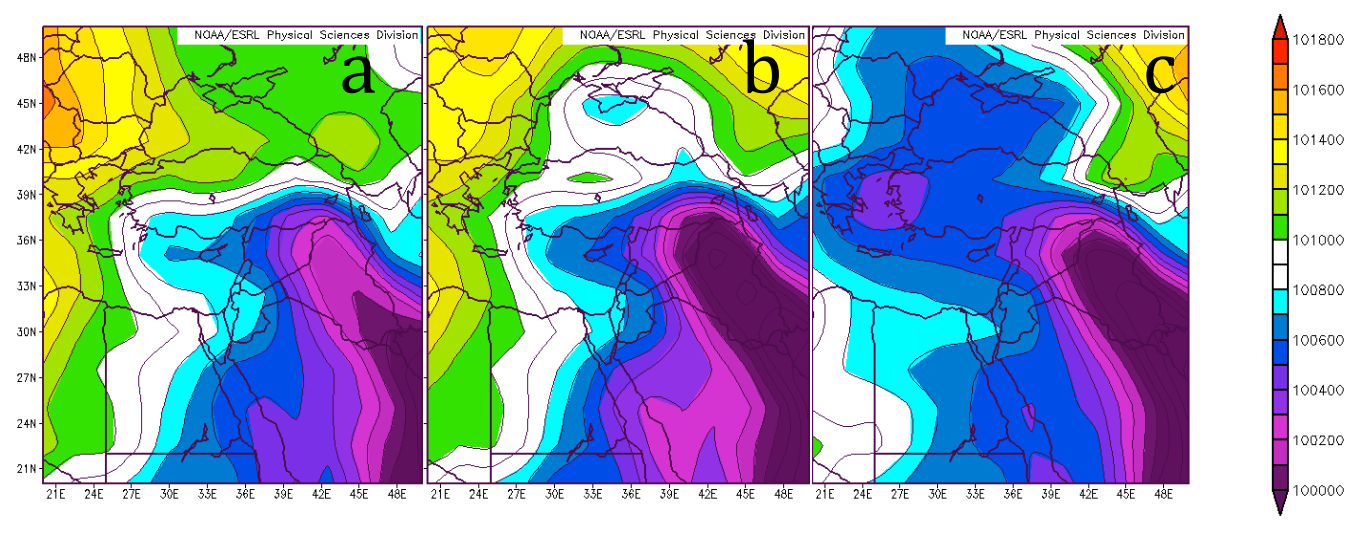

Fig. 2. Sea level pressure composite charts over the EM for (a) WPT, (b) DPT and (c) HW synoptic categories, for the ten selected days (see Table 1).

the atmosphere. Dayan et al. (1988) showed signifcant differences in mixing depth values for the main two synoptic categories (DPT and WPT) prevailing during the summer.

Figure 2 shows SLP charts used to derive the horizontal pressure gradient defined quantitatively by the surfacepressure difference $(\Delta P)$ between Nicosia, Cyprus and Cairo, Egypt, (Dayan et al., 2002). These fields were extracted from the Reanalysis NCEP/NCAR archive (Kalnay et al., 1996; Kistler et al., 2001) for the ten selected clear days of July 2010. The mixing layer depth, mean wind speed in the mixed layer and the ventilation coefficient were calculated from the 12:00 UTC Beit-Dagan (Israel) radiosonde (Table 1).

\subsection{SB detected by a single meteorological station and satellite data}

Alpert and Rabinovich-Hadar (2003) developed an automated method based on thresholds to detect the SBF. Their method relies on a subjective inspection of time series of different parameters from surface meteorological stations in an 
Table 1. Parameters used for the synoptic classification of the ten selected days.

\begin{tabular}{|c|c|c|c|c|c|c|c|c|c|}
\hline Date & $\begin{array}{r}\text { Synop. } \\
\text { Category }\end{array}$ & $\begin{array}{r}\Delta P \text { Nicosia, } \\
\text { Cairo } \\
{[\mathrm{hPa}]}\end{array}$ & Avg & $\begin{array}{r}\text { GPH500 } \\
\text { flow }^{\mathrm{a}}\end{array}$ & $\begin{array}{r}\text { Mean mixing } \\
\text { depths WS } \\
{\left[\mathrm{m} \mathrm{s}^{-1}\right]}\end{array}$ & $\begin{array}{r}\text { Mixing } \\
\text { depth } \\
{[\mathrm{m}]}\end{array}$ & Avg & $\begin{array}{r}\text { Ventilation } \\
\text { coefficient } \\
{\left[\mathrm{m}^{2} \mathrm{~s}^{-1}\right]}\end{array}$ & Avg \\
\hline $\begin{array}{l}25 \text { July } 2010 \\
26 \text { July } 2010 \\
27 \text { July } 2010\end{array}$ & HW & $\begin{array}{r}1.5 \\
-1.0 \\
1.0\end{array}$ & 0.5 & $\begin{array}{r}\text { Zonal } \\
\text { Anticycl. }\end{array}$ & $\begin{array}{l}4.5 \\
4.4 \\
4.4\end{array}$ & $\begin{array}{l}578 \\
420 \\
587\end{array}$ & 528 & $\begin{array}{l}2601 \\
1848 \\
2583\end{array}$ & 2344 \\
\hline $\begin{array}{l}5 \text { July } 2010 \\
6 \text { July } 2010 \\
7 \text { July } 2010 \\
16 \text { July } 2010\end{array}$ & WPT & $\begin{array}{r}1.0 \\
1.0 \\
1.0 \\
0\end{array}$ & 0.75 & Anticycl. & $\begin{array}{l}3.5 \\
3.3 \\
3.1 \\
3.5\end{array}$ & $\begin{array}{l}526 \\
401 \\
651 \\
606\end{array}$ & 546 & $\begin{array}{l}1841 \\
1303 \\
2018 \\
2121\end{array}$ & 1821 \\
\hline $\begin{array}{l}1 \text { July } 2010 \\
21 \text { July } 2010 \\
22 \text { July } 2010\end{array}$ & DPT & $\begin{array}{l}2.0 \\
2.5 \\
2.5\end{array}$ & 2.3 & Cyclonic & $\begin{array}{l}3.8 \\
5.0 \\
3.4\end{array}$ & $\begin{array}{r}1053 \\
1096 \\
910\end{array}$ & 1020 & $\begin{array}{l}4001 \\
5480 \\
3094\end{array}$ & 4192 \\
\hline
\end{tabular}

${ }^{\text {a }}$ Geopotential height at $500 \mathrm{hPa}(\mathrm{GPH} 500)$ is a descriptive measure of the cyclonic/anticyclonic flow in the upper atmosphere.

area of 20 by $40 \mathrm{~km}$ over the southern coast of Israel. They used data from two periods in July 1993 and 1994 representing the summer regardless of the differing synoptic circulation systems characterizing this season.

In this study, a 10 min interval time series of wind speed and direction that manifests the SB were used from 11 meteorological stations (Fig. 1). The SB threshold values obtained were: stabilization in wind direction $\left( \pm 8^{\circ}\right.$ for $\left.90 \mathrm{~min}\right)$, and increase of wind speed to 0.6 of its diurnal amplitude. These criteria were retrieved objectively using the whole data set, as explained in the next section. Figure $3 \mathrm{a}$ and $\mathrm{b}$ demonstrates the detection of the SB timing using the wind speed (Fig. 3a) and wind direction (Fig. 3b) thresholds in 7 July 2010, over the western Negev Desert (Halutza meteorological station, see Fig. 1) during WPT synoptic conditions. These criteria were searched in a time interval when the SB is expected to pass the meteorological station according to its distance from the coast. The time interval $\left(t_{\text {early }}: t_{\text {late }}\right)$ is set as follows:

$t_{\text {early }}=t_{\text {early }}^{\text {coast }}+\operatorname{dist} / v_{\max }$

$t_{\text {late }}=t_{\text {late }}^{\text {coast }}+\operatorname{dist} / v_{\text {min }}$

where $t_{\text {early }}^{\text {coast }}(10: 00 \mathrm{LT})$ and $t_{\text {late }}^{\text {coast }}(13: 00 \mathrm{LT})$ are the early and late time, during which the SBF is expected to cross the coastline eastwards at a typical speed of $2\left(v_{\min }\right)$ to 5 $\left(v_{\max }\right) \mathrm{m} \mathrm{s}^{-1}$, and dist is the distance from coastline. The objectively retrieved times for the SB are indicated by crosses in Fig. 3.

The description of SB timing derived from satellite, done independently, will follow. The wind speed and direction thresholds were optimized in an iterative manner against Spinning Enhanced Visible and Infrared Imager (SEVIRI) data. SEVIRI is mounted onboard Meteosat Second Generation (MSG) - the European geostationary satellite. SEVIRI has 11 spectral channels with $3 \mathrm{~km}$ spatial resolution at nadir and 15 min temporal resolution (Schmetz et al., 2002), enabling continuous detection. The archived data are freely available through the EUMETSAT Earth Observation portal at https://eoportal.eumetsat.int. The thermal impact of the SB on the surface temperature can be seen in Fig. 4. Channel 9 $(10.8 \mu \mathrm{m})$ brightness temperature (BT) data for the dates in Table 1 was used for the SBF detection.

Land surface temperature is affected by a number of factors, e.g. solar radiation, weather conditions such as air mass temperature, cloudiness and sea breeze. The solid red line in Fig. 3c shows the BT from the pixel collocated with Halutza meteorological station, at the same time interval as in Fig. $3 \mathrm{a}$ and $b$. The climatology (dotted line) was calculated using temporal Fourier analysis as in Lensky and Dayan (2011). The red line in Fig. $3 \mathrm{~d}$ is the deviation of the pixels BT from the expected climatology $(\Delta T)$, and the dashed line is the zero-difference-line. We expect the SB to decrease the surface temperature; therefore we looked for minimum in $\Delta T$ in the time interval when the SB is expected to pass in that pixel (Eq. 1).

\section{Results and discussion}

The diurnal variation of wind speed and direction typifying a WPT (7 July 2010) shows weak and variable winds until the onset of the SB at 12:00 LT (Fig. 3a and b). The stronger large-scale conditions characterizing DPT (21 July 2010), resulting in stronger westerly winds, which persist throughout the day, suppresses mesoscale processes (Fig. 3e and f). This is manifested also in the collocated satellite data in Fig. $3 \mathrm{~h}$ in which a large $\Delta T$ is observed from 06:30 LT persisting for nine hours, which is attributed to large-scale cold air advection. In Fig. 3d large $\Delta T$ is observed only from 12:00 LT, lasting for three hours, while wind azimuth stabilizes as westerlies and intensify. 

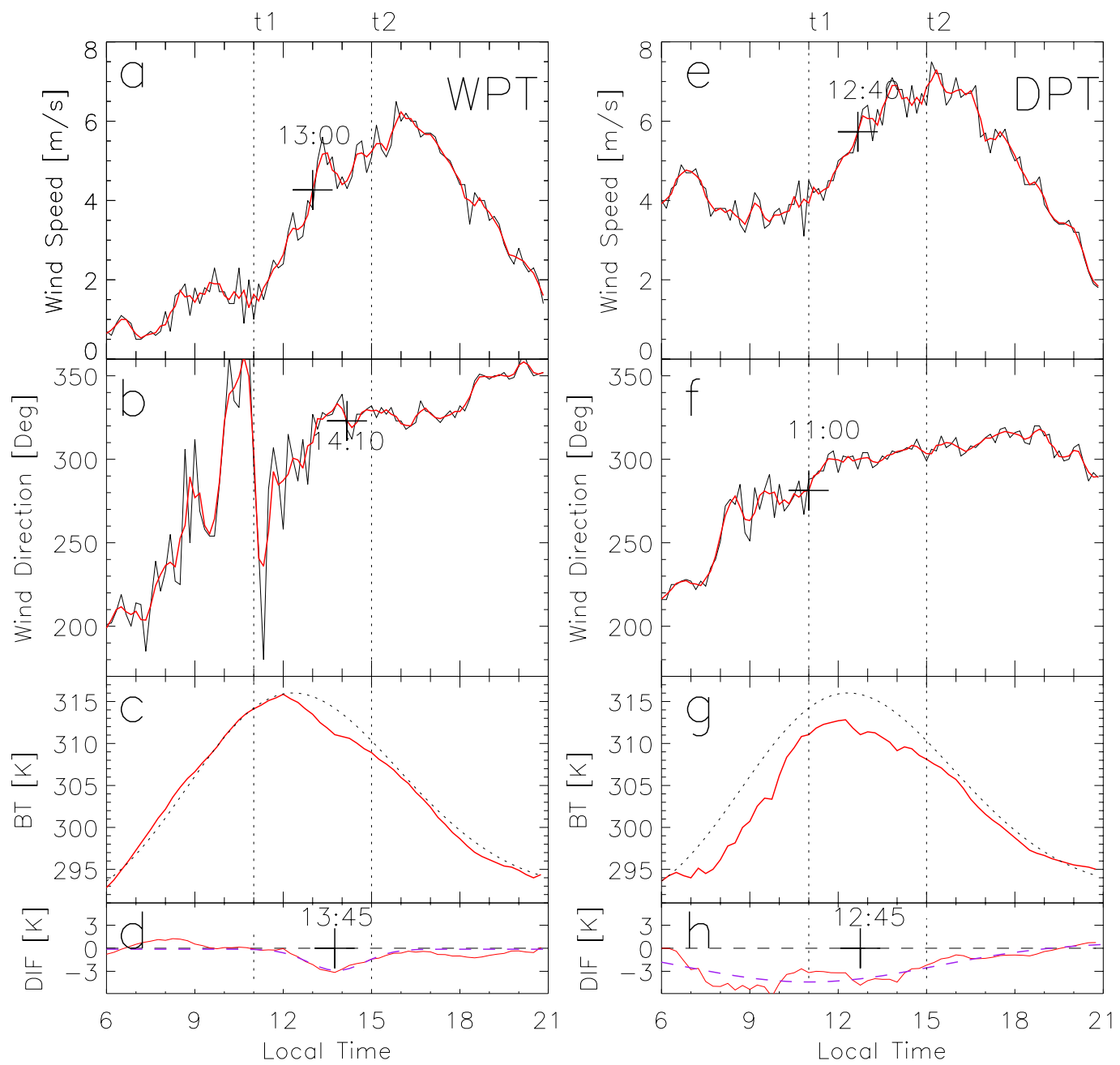

Fig. 3. Detecting the sea breeze using time series from 7 July 2010, representing WPT synoptic category, of wind speed (a) and wind direction (b) from Halutza meteorological station. The red lines in (a) and (b) are running average over three $10 \mathrm{~min}$. time steps. The red line in (c) represents time series of brightness temperature from MSG pixel collocated with Halutza meteorological station. The dotted line represents the climatological BT for that pixel. The thin red line in (d) is the deviation of the pixels BT from its expected climatological value (horizontal black dashed line). The SBF is searched in the time interval ( $\left.t_{\text {early }}: t_{\text {late }}\right)$ according to its distance from the coast. The maximal deviation is detected at 13:45 LT in (d). The dashed purple line in (d) is a Gaussian with $\sigma \sim 1 \mathrm{~h}$, typical to meso-scale disturbance. Panels $(\mathbf{e}, \mathbf{f}, \mathbf{g}, \mathbf{h})$ are the same as (a, b, c, d) for 21 July 2010, representing DPT synoptic category. Note the stronger winds (e), the uniform wind direction after 11:00 LT (f), and the large discrepancy between the MSG measured BT (red line) and the climatological values (dotted line) between 07:00 and 15:00 LT, representing synoptic scale cold advection featuring DPT (g). The Gaussian in (h) shows $\sigma>4 \mathrm{~h}$ representing a synoptic-scale disturbance, and does not fit the observed deviation as well as the Gaussian in (d) since the disturbance in this case stems from cold advection of synoptic scale nature.

In cases where sustained onshore synoptic flow mask the $\mathrm{SB}$, its detection can be regarded as false alarm. In order to avoid such false alarm cases, a parameter that estimates whether the "disturbance" $(\Delta T)$ is of a meso or synoptic scale nature was adopted. In Fig. 3d the deviation from climatology $(\Delta T)$ is presented as solid red line, together with a Gaussian (Eq. 2) simulating a disturbance generated by a mesoscale or synoptic-scale wind flow presented as dashed purple lines in Fig. 3d and h. $f(t)=$ const $+\frac{1}{\sigma \sqrt{2 \pi}} \cdot e^{-\frac{(t-\mu)^{2}}{2 \sigma^{2}}}$

where $t$ is the time, $\mu$ is the time of the maximal $\Delta T, \sigma$ is the standard deviation which estimates the duration of the disturbance, and $\sigma^{2}$ is the variance. The agreement between the Gaussian and the deviation from climatology is also quantified by calculating the sum square of the residuals between them (Moré and Wright, 1993). It is evident in Fig. 3d for 


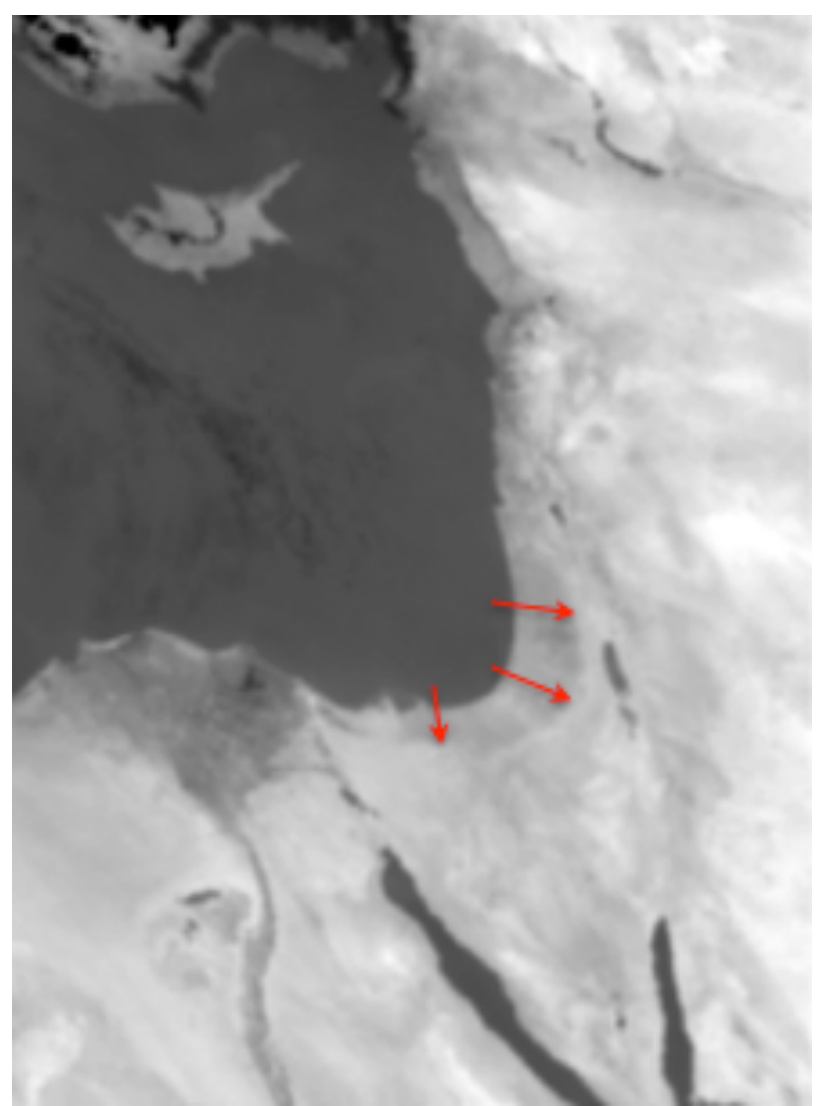

Fig. 4. MSG channel $9(10.8 \mu \mathrm{m})$ brightness temperature from 7 July 2010 14:00 LT. The three red arrows point to the thermal impact of the SB on the surface temperature. An animation depicting the progression of the SB from 09:30 to 17:00 LT can be found in the supplementary.

the WPT case that mesoscale feature is dominant $(\sigma \sim 1 \mathrm{~h})$ where the Gaussian fits nicely the deviation from climatology, as compared to the DPT case in Fig. 3h where the dashed purple line does not fit well the deviation from climatology, and the disturbance duration $(\sigma)$ exceeds $4 \mathrm{~h}$.

The scatter plot in Fig. 5 shows the relationship between the timing of the SB detected by all 11 surface meteorological stations for the ten days analyzed vs. the timing of the SB as detected by the collocated MSG pixels, as inferred by the maximum discrepancy of the measured BT from its climatological value $(\Delta T)$. Figure 5 a presents the timing of the SB using MSG data vs. the timing of the SB using the wind speed criterion for the weak horizontal pressure gradient synoptic categories (WPT and HW). Figure 5d shows the same for the strong horizontal pressure gradient (DPT). The timing of the SB for each meteorological station was calculated using the procedure shown in Fig. 3. The same method was adopted for the wind direction criteria (Fig. $5 \mathrm{~b}$ and e). An additional parameter combining both former parameters is shown in Fig. $5 \mathrm{c}$ and $\mathrm{f}$.
The correlations obtained, as expected, were higher for days characterized by weak synoptic scale forcing $\left(R^{2}=0.75\right)$ as compared to days classified as DPT $\left(R^{2}=0.5\right)$, where the dominant large scale westerly flow overrides the daytime land-sea differential surface heating. These conditions reflect the suppression of mesoscale phenomenon (Klaić et al., 2009; Planchon et al., 2006).

Satellite measurements at $10.8 \mu \mathrm{m}$ are dominated by the surface skin temperature, which lags behind the air temperature. This explains the observed bias in the SB timing using the wind speed criterion vs. that of the MSG (Fig. 5a and d). In addition, satellite measurements are column integrated, as compared to the surface meteorological data. The SB vertical structure behaves as a weak cold front, and as such, is detected first at shallow tropospheric layers, and only later at higher altitudes.

The correlations of Fig. 5 were also used to objectively derive the surface meteorological criteria for the timing of the SB. These criteria were optimized to attain the highest correlations in an iterative manner. By this procedure the best agreement between the satellite and surface meteorological stations perspective is achieved.

Geostationary satellite enables the best spatio-temporal observations of the dynamical processes on Earth. The methodology shown here to derive the timing of the SB from a single pixel enables a spatio-temporal analysis of the SB over larger domains including remote areas with no available surface data.

The colours in Fig. 6 represent the timing of the SB deduced from maximum deviation of the BT from its climatological value as demonstrated for a single pixel (Fig. 3d). Figure 6a shows the SB timing for 7 July 2010 over the EM and the North African coast under WPT conditions, and (Fig. 6b) for 21 July 2010, during DPT conditions. The gradual greenyellow-red colours depict the propagation of the SB from the coast inland, where green represents 11:30-13:30, yellow 13:30-14:30, and red from 14:30 to 16:00 LT. This analysis is based on time series derived from individual pixels independently from adjacent pixels. The obtained colour sequences reflect the propagation of the disturbance. The orientation of these sequences with regard to the coastline, and the timing of its propagation, indicates that the identified process is the SB.

To eliminate pixels with false alarm detection, we applied the two criteria presented in Fig. 3. The first is selecting pixels with mesoscale disturbance duration $(\sigma<2 \mathrm{~h})$. For these pixels we apply a second criterion based on a threshold reflecting the degree of agreement between the model and the disturbance, where pixels that did not meet this criterion were excluded. These criteria were applied to all the pixels as displayed in Fig. 6.

Figure 6 depicts the SB timing after filtering out pixels identified as false alarm, showing only areas with gradual colors featuring the onshore SB penetration. The inland desert subtropical regions at the bottom of Fig. 6 with 


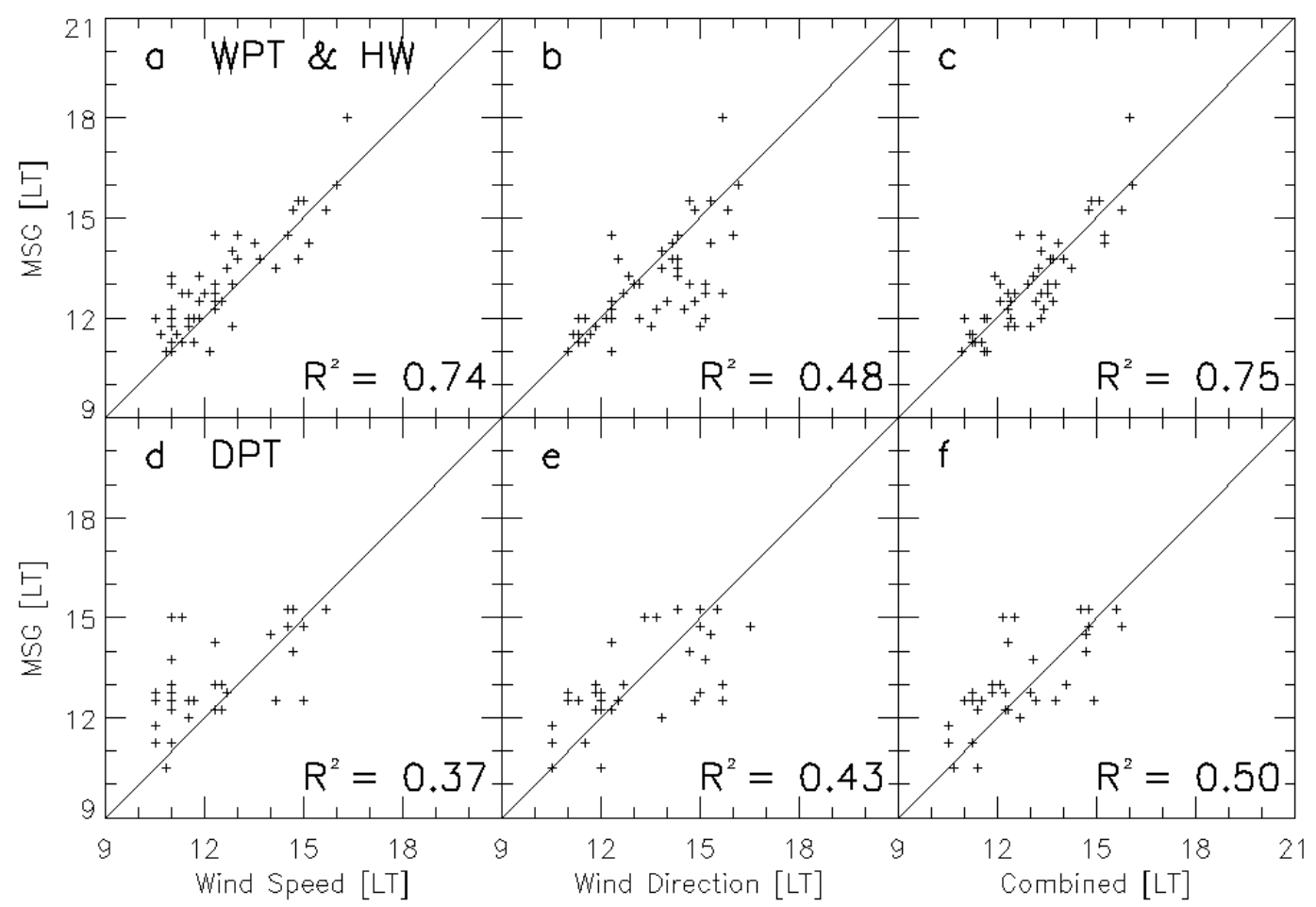

Fig. 5. Scatter plots of SB timing (LT) as detected by surface stations (a, $\mathbf{d}$-wind speed, $\mathbf{b}$, e-wind direction and $\mathbf{c}$, $\mathbf{f}$-combined) vs. satellite (MSG) for WPT and HW (a, b, c) and DPT (d, e, f) synoptic categories.

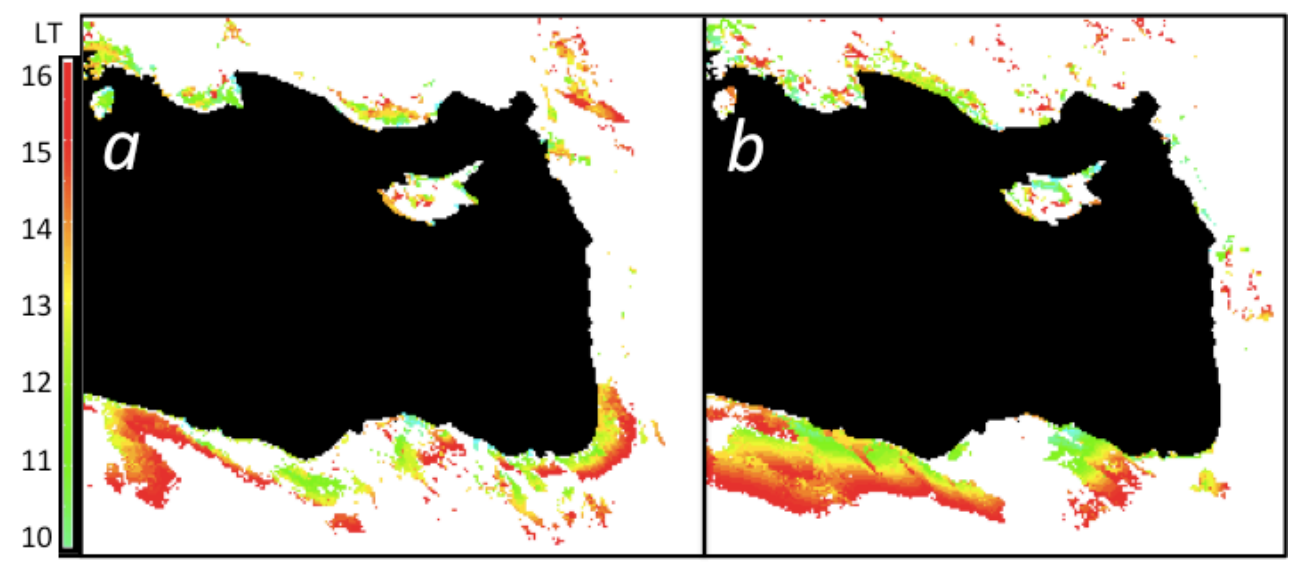

Fig. 6. Timing of the SB in local time displayed for (a) 7 July 2010 (WPT), and (b) 21 July 2010 (DPT). The green-yellow-red color bar represents the timing of maximum deviation of MSG $10.8 \mu \mathrm{m}$ brightness temperature from its climatological value (see Fig. $3 \mathrm{~d}$ ) for pixels with $\sigma<2 \mathrm{~h}$ and passed the "agreement" threshold as demonstrated for a single pixel in Fig. 3d and h. The gradual green-yellow-red colour pattern depicts the SB propagation.

extreme hot surface temperature at noontime, intensify the SB circulation. Moreover, the contrast between the cool marine air mass flowing over the hot underlying ground facilitates the detection of the propagation of the abovementioned thermal disturbance. Noteworthy, the stronger northerly SB flow over North Africa in Fig. 6a which penetrates faster and further inland as compared to the SB over the southern coast of Israel in Fig. 6b. 


\section{Summary}

In this study remote sensing data and concurrent field measurements were used to detect and characterize the SB in clear sky conditions in the summer, when the conditions for this mesoscale circulation system are most favorable. Visualizing timing of the SB retrieved from remote sensing data enabled the distinction of SB behavior under different synoptic categories. Over desert regions the strong thermal contrast enables detection of the SB under synoptic conditions characterized by strong horizontal pressure gradient (DPT). The SB was identified by surface measurements in an earlier time of the day, with respect to the satellite column integrated measurements. This method enables detection and timing of the SB over desert regions where clouds and field measurements are scarce, and is applicable worldwide.

Acknowledgements. The authors thank the Ministry of Agriculture and Rural Development and the Ministry of Environment Protection for the meteorological surface data, University of Wyoming -Department of Atmospheric Science, for the sounding data, METI and NASA for the ASTER GDEM (Global Digital Elevation Model) terrain data and EUMETSAT for the MSG data. The authors thank the reviewers for their valuable comments that improved this manuscript.

Edited by: G. Vaughan

\section{References}

Alpert, P. and Rabinovich-Hadar, M.: Pre- and Post-Sea-Breeze Frontal Lines - A Meso- $\gamma$-Scale Analysis over South Israel, J. Atmos. Sci., 60, 2994-3008, doi:10.1175/15200469(2003)060<2994:PAPFLM>2.0.CO;2, 2003.

Alpert, P., Cohen, A., Neumann, J., and Doron, E.: A Model Simulation of the Summer Circulation from the Eastern Mediterranean past Lake Kinneret in the Jordan Valley, Month. Weather Rev., 110, 994-1006, doi:10.1175/15200493(1982)110<0994:AMSOTS > 2.0.CO;2, 1982.

Alpert, P., Tannhauser, D. S., Leshem, Y., Kravitz, A., and Rabinovich-Hadar, M.: commentary and analysis: Migrating Soaring Birds Align along Sea-Breeze Fronts, First Evidence from Israel, B. Am. Meteorol. Soc., 81, 1599-1601, doi:10.1175/1520-0477(2000)081<1599:CAAMSB > 2.3.CO;2, 2000.

Azorin-Molina, C., Connell, B. H., and Baena-Calatrava, R.: SeaBreeze Convergence Zones from AVHRR over the Iberian Mediterranean Area and the Isle of Mallorca, Spain, J. Appl. Meteorol. Clim., 48, 2069-2085, doi:10.1175/2009JAMC2141.1, 2009.

Azorin-Molina, C., Chen, D., Tijm, S., and Baldi, M.: A multi-year study of sea breezes in a Mediterranean coastal site: Alicante (Spain), Int. J. Climatol., 31, 468-486, 2011.

Chen, F., Miao, S., Tewari, M., Bao, J.-W., and Kusaka, H.: A numerical study of interactions between surface forcing and sea breeze circulations and their effects on stagnation in the greater Houston area, J. Geophys. Res., 116, D12105, doi:10.1029/2010JD015533, 2011.

Crosman, E. and Horel, J.: Sea and Lake Breezes: A Review of Numerical Studies, Bound.-Lay. Meteorol., 137, 1-29, 2010.

Dalu, G. A., Baldi, M., Pielke, R. A., and Leoncini, G.: Mesoscale Nonhydrostatic and Hydrostatic Pressure Gradient Forces Theory, J. Atmos. Sci., 60, 2249-2266, doi:10.1175/15200469(2003)060<2249:MNAHPG>2.0.CO;2, 2003.

Damato, F., Planchon, O., and Dubreuil, V.: A remote-sensing study of the inland penetration of sea-breeze fronts from the English Channel, Weather, 58, 219-226, 2003.

Dayan, U., Shenhav, R., and Graber, M.: The Spatial and Temporal Behavior of the Mixed Layer in Israel, J. Appl. Meteorol., 27, 1382-1394, doi:10.1175/15200450(1988)027<1382:TSATBO > 2.0.CO;2, 1988.

Dayan, U., Lifshitz-Goldreich, B., and Pick, K.: Spatial and Structural Variation of the Atmospheric Boundary Layer during Summer in Israel - Profiler and Rawinsonde Measurements, J. Appl. Meteorol., 41, 447-457, doi:10.1175/15200450(2002)041<0447:SASVOT>2.0.CO;2, 2002.

Drobinski, P., Bastin, S., Dabas, A., Delville, P., and Reitebuch, O.: Variability of three-dimensional sea breeze structure in southern France: observations and evaluation of empirical scaling laws, Ann. Geophys., 24, 1783-1799, doi:10.5194/angeo-241783-2006, 2006.

Federico, S., Pasqualoni, L., De Leo, L. and Bellecci, C.: A study of the breeze circulation during summer and fall 2008 in Calabria, Italy, Atmos. Res., 97, 1-13, doi:10.1016/j.atmosres.2010.02.009, 2010.

Grønås, S. and Sandvik, A. D.: Numerical simulations of sea and land breezes at high latitudes, Tellus A, 50, 468-489, 1998.

Hendrickson, J. and MacMahan, J.: Diurnal sea breeze effects on inner-shelf cross-shore exchange, Cont. Shelf Res., 29, 21952206, doi:10.1016/j.csr.2009.08.011, 2009.

Kalnay, E., Kanamitsu, M., Kistler, R., Collins, W., Deaven, D., Gandin, L., Iredell, M., Saha, S., White, G., Woollen, J., Zhu, Y., Leetmaa, A., Reynolds, R., Chelliah, M., Ebisuzaki, W., Higgins, W., Janowiak, J., Mo, K. C., Ropelewski, C., Wang, J., Jenne, R., and Joseph, D.: The NCEP/NCAR 40-Year Reanalysis Project, B. Am. Meteorol. Soc., 77, 437-471, doi:10.1175/15200477(1996)077<0437:TNYRP>2.0.CO;2, 1996.

Kistler, R., Collins, W., Saha, S., White, G., Woollen, J., Kalnay, E., Chelliah, M., Ebisuzaki, W., Kanamitsu, M., Kousky, V., van den Dool, H., Jenne, R., and Fiorino, M.: The NCEP/NCAR 50-Year Reanalysis: Monthly Means CD-ROM and Documentation, B. Am. Meteorol. Soc., 82, 247-267, doi:10.1175/15200477(2001)082<0247:TNNYRM>2.3.CO;2, 2001.

Klaić, Z. B., Pasarić, Z., and Tudor, M.: On the interplay between sea-land breezes and Etesian winds over the Adriatic, J. Marine Syst., 78, Supplement, S101-S118, doi:10.1016/j.jmarsys.2009.01.016, 2009.

Lensky, I. M. and Dayan, U.: Detection of Finescale Climatic Features from Satellites and Implications for Agricultural Planning, B. Am. Meteorol. Soc., 92, 1131-1136, doi:10.1175/2011BAMS3160.1, 2011.

Levy, I., Dayan, U., and Mahrer, Y.: A five-year study of coastal recirculation and its effect on air pollutants over the East Mediterranean region, J. Geophys. Res., 113, D16121, doi:10.1029/2007JD009529, 2008. 
Mangia, C., Schipa, I., Tanzarella, A., Conte, D., Marra, G. P., Marcello Miglietta, M., and Rizza, U.: A numerical study of the effect of sea breeze circulation on photochemical pollution over a highly industrialized peninsula, Meteorol. Appl, 17, 19-31, doi:10.1002/met.147, 2010.

Moré, J. J. and Wright, S. J.: Optimization Software Guide, Society for Industrial and Applied Mathematics, Philadelphia, PA 19104-2688 USA, available at: http://www.ec-securehost.com/ SIAM/FR14.html, 1993.

Neumann, J. and Mahrer, Y.: A Theoretical Study of the Land and Sea Breeze Circulation, J. Atmos. Sci., 28, 532-542, doi:10.1175/1520-0469(1971)028<0532:ATSOTL > 2.0.CO;2, 1971.

Papanastasiou, D. K. and Melas, D.: Climatology and impact on air quality of sea breeze in an urban coastal environment, Int. J. Climatol., 29, 305-315, doi:10.1002/joc.1707, 2009.

Papanastasiou, D. K., Melas, D., and Lissaridis, I.: Study of wind field under sea breeze conditions; an application of WRF model, Atmos. Res., 98, 102-117, doi:10.1016/j.atmosres.2010.06.005, 2010a.

Papanastasiou, D., Melas, D., Bartzanas, T., and Kittas, C.: Temperature, comfort and pollution levels during heat waves and the role of sea breeze, Int. J. Biometeorol., 54, 307-317, doi:10.1007/s00484-009-0281-9, 2010b.
Planchon, O., Damato, F., Dubreuil, V., and Gouery, P.: A method of identifying and locating sea-breeze fronts in northeastern Brazil by remote sensing, Meteorol. Appl., 13, 225-234, doi:10.1017/S1350482706002283, 2006.

Qian, T., Epifanio, C. C., and Zhang, F.: Linear Theory Calculations for the Sea Breeze in a Background Wind: The Equatorial Case, J. Atmos. Sci., 66, 1749-1763, doi:10.1175/2008JAS2851.1, 2009.

Rao, P. A., Fuelberg, H. E., and Droegemeier, K. K.: HighResolution Modeling of the Cape Canaveral Area LandWater Circulations and Associated Features, Month. Weather Rev., 127, 1808-1821, doi:10.1175/15200493(1999)127<1808:HRMOTC>2.0.CO;2, 2011.

Schmetz, J., Pili, P., Tjemkes, S., Just, D., Kerkmann, J., Rota, S., and Ratier, A.: An Introduction to Meteosat Second Generation (MSG), B. Am. Meteorol. Soc., 83, 977-992, 2002.

Soler, M., Arasa, R., Merino, M., Olid, M., and Ortega, S.: Modelling Local Sea-Breeze Flow and Associated Dispersion Patterns Over a Coastal Area in North-East Spain: A Case Study, Bound.-Lay. Meteorol., 140, 37-56, 2011.

Young, K. and Zhang, M.: Analytic study of sea-land breezes, Adv. Atmos. Sci., 16, 263-278, 1999. 